\title{
Desenvolvimento do currículo no ensino superior: desafios para a docência universitária
}

Diana Mesquita, Maria-Assunção Flores y Rui M. Lima

\begin{abstract}
RESUMO
Este artigo baseia-se em um projeto de estudos mais amplo e procura discutir os desafios que se colocam à docência universitária, particularmente no que diz respeito ao desenvolvimento do currículo no ensino superior. O primeiro desafio aponta para a relação entre a planificação do professor e a sua ação pedagógica, o processo de seleção dos conteúdos e as estratégias de ensino. O segundo desafio reforça a importância da criação de espaços interdisciplinares com vista ao desenvolvimento de competências dos alunos. E o terceiro desafio coloca a ênfase na avaliação, enquanto um dos principais elementos potenciadores da inovação curricular. Não são muitos os estudos que discutem de forma aprofundada, os pressupostos curriculares e pedagógicos inerentes à docência universitária. Assim, estes desafios constituem um contributo relevante para esta questão, nomeadamente ao nível das suas implicações para o trabalho e desenvolvimento profissional dos professores.
\end{abstract}

Palavras chave: docência universitária; desenvolvimento do currículo; ensino superior, Portugal.

Diana Mesquita

diana@dps.uminho.pt Portuguesa. Doutora em Ciências da Educação, na especialidade de Desenvolvimento Curricular pelo Instituto de Educação da Universidade do Minho, Portugal. Coordenadora principal do projeto PIPBIRA (Programa de Inovação Pedagógica em Itabira); tem participado em outros projetos nacionais e internacionais relacionados com o Ensino Superior. Temas de investigação: inovação pedagógica e curricular no ensino superior, desenvolvimento e avaliação de competências, cooperação entre universidades e empresas, educação em engenharia com ênfase na formação inicial, perfil profissional e estratégias de aprendizagem ativa.

Maria-Assunção Flores

aflores@ie.uminho.pt

Portuguesa. Doutora em Educação, pela Universidade de Nottingham, Inglaterra. Professora Associada com Agregação do Instituto de Educação da Universidade do Minho, Portugal. Presidente da International Study Association on Teachers and Teaching, Diretora Executiva da revista Teachers and Teaching Theory and Practice, Diretora da revista European Journal of Teacher Education. Temas de investigação: formação inicial de professores, avaliação e ensino superior.

Rui M. Lima

rml@dps.uminho.pt Portugues. Doutor em Engenharia de Produção e Sistemas, pela Escola de Engenharia da Universidade do Minho, Portugal. Professor Associado do Departamento de Produção e Sistemas da Escola de Engenharia da Universidade do Minho, Portugal. Temas de investigação: ensino e/ou pesquisa em engenharia e gestão industrial, com foco atual nas seguintes áreas: gestão de projetos, gestão da produção, lean manufacturing, educação em engenharia, university-business cooperation e project-based learning (PBL). 


\title{
Desarrollo del currículo en la enseñanza superior: desafíos para la docencia universitaria
}

\section{RESUMEN}

Este artículo se basa en un proyecto de investigación más amplio y busca discutir los desafíos que se plantean a la docencia universitaria, particularmente en lo que se refiere al desarrollo del currículo en la enseñanza superior. El primer desafío apunta a la relación entre la planificación del profesor y su acción pedagógica, el proceso de selección de los contenidos y las estrategias de enseñanza. El segundo desafío refuerza la importancia de la creación de espacios interdisciplinarios para el desarrollo de competencias de los alumnos. Y el tercer desafío pone el énfasis en la evaluación, como uno de los principales elementos potenciadores de la innovación curricular. No son muchos los estudios que discuten a profundidad los supuestos curriculares y pedagógicos inherentes a la docencia universitaria. Así, estos desafíos constituyen una contribución relevante a esta cuestión, en particular a nivel de sus implicaciones para el trabajo y el desarrollo profesional de los docentes.

Palabras clave: docencia universitaria; desarrollo del currículo; enseñanza superior; Portugal.

\section{Curriculum development in higher education: challenges for university teaching}

\begin{abstract}
This article is based on a broader research project and aims to discuss the challenges faced by university teaching, particularly with regard to curriculum development in higher education. The first challenge points to the relationship between teacher planning and pedagogical action, content selection processes and teaching strategies. The second challenge reinforces the importance of creating interdisciplinary spaces for the development of the students' competences. And the third challenge places emphasis on assessment as one of the key enhancers of curriculum innovation. There are not many studies that discuss in depth the curricular and pedagogical assumptions attached to university teaching. These challenges therefore make a significant contribution to this issue, in particular as regards their implications for teachers' work and professional development.
\end{abstract}

Key words: university teaching; curriculum development; higher education; Portugal.

Recepción: 28/11/15. Aprobación: 23/02/17. 


\section{Ensino superior: contextos e protagonistas}

Nas últimas décadas, o ensino superior tem sido marcado por mudanças significativas que tiveram particular impacto na relação das universidades com a sociedade, isto é, as instituições de ensino superior deixaram de estar alienadas da dinâmica social para participarem, cada vez mais, nos contextos sociais, culturais, políticos e económicos em que estão inseridas (Barnett, 1994).

De acordo com Toohey (2002), entre os fatores que contribuíram para as mudanças ocorridas estão a alteração do perfil do aluno, a investigação sobre o ensino e a aprendizagem, que ampliou os espaços de reflexão em relação aos contextos e às práticas do ensino superior, e a organização das instituições de ensino superior que se revela cada vez mais complexa e com uma oferta formativa cada vez mais diversificada. Consequentemente, "a ideia do ensino universitário pluralizou-se e está a diversificar-se, a diferenciar-se e a segmentar-se" (Magalhães, 2011, p. 625), refletindo-se em todas as suas dimensões. A este respeito Zabalza (2002) sugere quatro eixos que caracterizam as diferentes dimensões inerentes ao contexto do ensino superior. O primeiro eixo referese à relação universidade-política universitária, em que a realidade histórica da universidade é evidenciada através da sua missão e valores definidos. O segundo eixo diz respeito à articulação entre os materiais do currículo e a ciência e tecnologia, na medida em que, segundo o autor, ela constitui a essência formativa do trabalho universitário. O terceiro eixo coloca ênfase nos professores como agentes decisivos nos processos de inovação e mudança das universidades. O quarto eixo relaciona-se com os alunos cujas motivações, expectativas, opções e perspetivas também influenciam as práticas das universidades. Adicionalmente, o mercado de trabalho é igualmente considerado na medida em que direciona os interesses dos alunos e futuros profissionais. É, neste sentido, que a perspetiva de Zabalza (2002) sobre o papel das universidades procura integrar as suas principais dimensões, considerando o contexto atual em que se inserem:

\begin{abstract}
“(...) está se dizendo às universidades que não se contentem em apenas transmitir a ciência, mas que a criem (isto é, elas devem combinar a docência e a pesquisa); que deem um sentido prático e profissionalizante à formação que oferecem aos estudantes; que façam tudo isso sem se fechar em si mesmas: façam-no em contacto com o meio social, económico e profissional com o qual devem colaborar" (p. 20).
\end{abstract}

O ensino superior assume-se como um "espaço de decisões formativas" (Esteves, 2008, p. 103), decorrentes de contextos e pressões externas que influenciam as perspetivas e as expectativas dos agentes que nela se inserem, reclamando novas formas de ensinar e aprender e potenciando contextos cooperativos e articulados com o mundo do trabalho.

Neste ponto de vista, não é surpreendente a relevância que as questões curriculares e pedagógicas têm assumido no contexto do ensino superior, nomeadamente ao nível da qualidade dos programas de ensino (Barnett \& Coate, 2005) (Barnett \& Coate, 2005), dos modos de melhorar os processos de ensino e aprendizagem (Ramsden, 2004), da forma como os professores podem inovar a sua prática (Cowan, 2006) ou do modo como o currículo pode ser concebido, desenvolvido e avaliado (Toohey, 2002). Efetivamente, só a partir da década de 90 é que emergem estudos relativos à pedagogia no ensino superior que remetem para aquilo que se entende por pedagogia universitária: "o saber disponível para ser ensinado e aprendido" (Esteves, 2008, p. 103). Um contributo relevante sobre esta problemática decorre da investigação desenvolvida por Vieira et al. (2002) onde é destacada a necessidade de uma cultura pedagógica de qualidade assente em oitos princípios que visam uma pedagogia universitária transformadora e emancipatória: 
Intencionalidade: a ação pedagógica desenvolve-se numa direção assente em pressupostos e finalidades relativos à educação formal e à relação entre esta e a sociedade, direcionando-se a uma formação integrada, de âmbito científico, cultural, técnico/profissionalizante, pessoal e social;

Transparência: a ação pedagógica integra a explicitação dos pressupostos e finalidades de formação que a orientam, da natureza da metodologia seguida, dos processos/percursos de aprendizagem e dos parâmetros de avaliação adotados;

Coerência: a ação pedagógica é coerente com os pressupostos e finalidades de formação que a orientam, com a natureza dos conteúdos disciplinares e com os métodos de avaliação adotados;

Relevância: a ação pedagógica integra expectativas, necessidades, ritmos e interesses diferenciados, mobiliza e promove saberes, linguagens e experiências relevantes à futura profissão, promove o contato com a realidade socioprofissional e perspetiva o currículo de forma articulada;

Reflexividade: a ação pedagógica promove o pensamento divergente e o espírito crítico, integrando uma reflexão crítica sobre os seus pressupostos e finalidades, os conteúdos, a metodologia seguida, os parâmetros e métodos de avaliação, os processos/percursos de aprendizagem, o papel das disciplinas no currículo e a relação deste com a realidade socioprofissional;

Democraticidade: a ação pedagógica assenta em valores de uma cidadania democrática, sentido de justiça, respeito pela diferença, liberdade de pensamento e expressão, comunicação e debate de ideias, negociação de decisões, colaboração e interajuda;

Auto direção: a ação pedagógica desenvolve atitudes e capacidades de autogestão da aprendizagem, definição de metas e planos de trabalho autodeterminados, autoavaliação e estudo independente, curiosidade intelectual e vontade de aprender, sentido de autoestima e autoconfiança;

Criatividade/inovação: a ação pedagógica estimula processos de compreensão e intervenção, com implicações profissionais e sociais, promovendo uma interpretação pessoal e uma visão pluri/inter/ transdisciplinar do conhecimento e da realidade, capacidades de pesquisa e de resolução de problemas, desenvolvimento de projetos pessoais, capacidades de intervenção no contexto profissional e atitudes de abertura à inovação.

Estes princípios são essenciais para analisar a complexidade inerente à pedagogia universitária. Um estudo recente que assentou nestes princípios para conhecer as percepções de docentes universitários portugueses sobre o ensino e a qualidade da pedagogia reforçou a necessidade de desenvolver mais investigação sobre a qualidade da pedagogia universitária considerando o desenvolvimento profissional docente como uma problemática central para a inovação pedagógica e curricular (Veiga-Simão, Flores, Barros, Fernandes \& Mesquita, 2015).

Neste contexto, este artigo tem por objetivo apresentar e discutir os desafios que se colocam à docência universitária, particularmente no que diz respeito ao desenvolvimento do currículo no ensino superior.

\section{Desenvolvimento do currículo no ensino superior}

De acordo com Barnett e Coate (2005), o termo currículo no contexto do ensino superior, é um termo perdido, na medida em que a sua conceitualização assume formas diversas, muitas vezes difusas e até contraditórias. No ensino superior o currículo é, geralmente, entendido com sendo uma disciplina ou a organização das disciplinas que compõem um determinado curso (Fraser \& Bosanquet, 2006). Tornase, por isso, imperativo discutir e refletir sobre este conceito, tal como Barnett et al. (2001) sugerem: "o currículo merece uma atenção profissional de pleno direito que deve ser mantida de forma consistente" ( $p$. 448). Este pressuposto não é, contudo, recente e, por essa razão, Fensham (1977) apresenta sete dimensões a considerar na definição de currículo no contexto do ensino superior. Segundo o autor, estas dimensões, 
não só contribuem para a concetualização do currículo, como também permitem comparar cursos de ensino superior de diferentes instituições, monitorizar as mudanças verificadas ao longo do tempo de um determinado curso ou área de conhecimento e ainda disseminar práticas de inovação curricular.

Neste sentido, um dos principais pressupostos refere-se à importância de identificar os conhecimentos prévios e as competências dos alunos no momento em que ingressam no ensino superior (dimensão 1); desta forma, a instituição e os cursos podem delinear estratégias adequadas ao perfil dos alunos, que são cada vez mais diversificados (dimensão 2). Ao nível do papel do professor, o autor coloca a ênfase na utilização de apoios "extra" que permitam tornar a aula mais atrativa para os alunos, tais como atividades que promovam a participação ativa dos alunos (dimensão 3). Para tal, é fundamental planear e organizar o processo de ensino e aprendizagem, considerando os diferentes estilos de aprendizagem (dimensão 4). O autor defende ainda que os alunos devem escolher como querem aprender e o que querem aprender e, assim, a flexibilidade torna-se um princípio a considerar quando se aborda e pensa criticamente sobre o currículo (dimensão 5). Respeito àquilo que os alunos querem aprender, o autor sugere a necessidade de ampliar o espetro dos conteúdos, incluindo tópicos gerais que vão para além da área disciplinar que os alunos frequentam (dimensão 6). Das dimensões apresentadas sobressai, claramente, uma abordagem do currículo centrada na aprendizagem do aluno, daí que a avaliação (dimensão 7), como elemento nuclear do currículo, contemple processos e práticas centradas na monitorização e acompanhamento da aprendizagem do aluno ao longo do processo. Em suma, as sete dimensões sugeridas por Fensham (1977) podem ser consideradas atuais para uma orientação concetual do currículo no ensino superior, entendido "[...] como um artefacto para refletir e decidir acerca das questões educativas fundamentais do porquê, para quê, como e quando ensinar e aprender" (Alonso, 2000, p. 34).
Segundo Barnett et al. (2001), as mudanças relativas ao conceito de currículo no ensino superior estão relacionadas com a própria evolução do ensino superior, emergindo diferentes perspetivas, refletindo o seu desenvolvimento, mas tal não significa que sejam dicotómicas e incompatíveis, pois dependem dos contextos em que se situam. De acordo com os autores, o grande desafio do desenvolvimento curricular no ensino superior é a integração das suas várias dimensões. Esta é uma perspetiva amplamente defendida por Biggs (1996) cujo conceito de constructive alignment é considerado pelo autor como fundamental para a qualidade do ensino e da aprendizagem no ensino superior. Trata-se de um conceito que procura destacar a articulação de todos os elementos do currículo que, quando em sintonia, contribuem para que os alunos alcancem os resultados de aprendizagem. A este respeito, Zabalza (2009) apresenta um quadro de referência para avaliar a qualidade do ensino nas instituições de ensino superior que congrega um conjunto de dez elementos:

1. Planeamento: reflete a tomada de decisão do professor relativamente à forma como organiza o processo de ensino e aprendizagem. O planeamento incorpora, por isso, todos os elementos a considerar no desenvolvimento do currículo e que apresentamos de seguida.

2. Metodologia: refere-se às atividades e estratégias a serem desenvolvidas, a fim de os alunos atingirem os resultados de aprendizagem previamente definidos e, por isso, revela a intencionalidade do professor em relação ao contexto educacional.

3. Conteúdos: envolve um processo complexo de seleção dos conteúdos que se consideram mais relevantes para que possam ser compreendidos e desenvolvidos pelos alunos num determinado ambiente de aprendizagem.

4. Novas tecnologias: a sua utilização tem por objetivo potenciar a aprendizagem dos alunos, tornandoa mais atrativa e interativa para os alunos em 
articulação com outros elementos do currículo, por exemplo, na produção do material de apoio.

5. Ambiente de aprendizagem: a configuração do espaço é decisiva para os contextos de ensino e aprendizagem, uma vez que potencia a ação docente no sentido de ampliar o impacto formativo da abordagem de ensino utilizada.

6. Apoio ao aluno: o papel do professor adquire aqui particular relevância, na medida em que deve prever e definir estratégias de apoio e orientação às necessidades do aluno no sentido de potenciar a evolução da sua aprendizagem e o desenvolvimento de competências.

7. Material de apoio: remete para uma das formas de comunicação entre aluno e professor no contexto do processo de ensino e aprendizagem. O material de apoio pode ir para além da organização dos conteúdos, incorporando também as fontes de informação úteis (e.g. bibliografia), as dificuldades que são habitualmente sentidas pelos alunos ou a apresentação das atividades a desenvolver e explicitação do propósito e objetivo no âmbito da disciplina.

8. Colaboração docente: trata-se de uma dimensão necessária à conceção e desenvolvimento do currículo e, possivelmente, aquela que pressupõe um maior desafio, na medida em que implica uma interação entre pares, considerando contextos e abordagens interdisciplinares, em que os professores partilham ideias acerca da forma como os alunos aprendem, indo para além da forma como ensinam.

9. Avaliação: a atividade docente é amplamente marcada pelos processos avaliativos, sendo uma das maiores preocupações dos professores e estudantes do ensino superior. É também a partir da avaliação que se torna visível se o processo de ensino e aprendizagem se encontra curricularmente coerente e articulado.

10. Revisão do processo: é considerado um momento de avaliação final, em que se espera uma análise e reflexão sobre uma aula, uma disciplina ou o curso, resultando em propostas e sugestões de melhoria a serem incluídas no planeamento seguinte.

Apesar de uma descrição isolada, estes elementos, na conceção, desenvolvimento e avaliação do currículo, devem ser vistos de forma articulada e consistente e o professor é o agente principal neste processo, pela forma como integra estes elementos de modo a potenciar a aprendizagem dos alunos e como pode, deste modo, contribuir para a inovação curricular no ensino superior. Este pressuposto reforça o contributo deste artigo que visa apresentar os desafios da docência universitária, considerando as questões curriculares e pedagógicas inerentes ao ensino superior. Antes de apresentar e discutir estes desafios, importa conhecer o contexto da investigação no qual este artigo se enquadra, bem como a abordagem metodológica utilizada.

\section{Contexto do estudo}

Este artigo enquadra-se num projeto de pesquisa mais alargado, desenvolvido no contexto do ensino superior e que tem como objetivo principal contribuir para a melhoria da qualidade dos programas de formação na área das Engenharias, Ciências e Tecnologias. Com vista a aprofundar a análise das dimensões curriculares e pedagógicas da formação inicial optou-se por estudar um caso em particular, o Mestrado Integrado em Engenharia e Gestão Industrial (MIEGI) da Universidade do Minho, Portugal.

O MIEGI foi um curso criado em 1975/76, sendo inicialmente designado de Engenharia de Produção e tornou-se o primeiro de Portugal nesta área da Engenharia. Tal justificou-se por uma rápida evolução das novas tecnologias, pela emergência da internacionalização e pela liberalização dos mercados que começaram a exigir às empresas portuguesas maior eficiência produtiva e competitividade. Para responder a estes desafios, as empresas, para além de recursos de diversa ordem (técnicos, financeiros, etc.), necessitavam 
de profissionais qualificados para funções de gestão integrada entre os diferentes setores e processos. Em 2001 identificou-se uma quebra acentuada na procura da Engenharia de Produção no ensino superior e especulava-se que tal estaria associado à falta de um entendimento geral do que seria a Engenharia de Produção e o que faria um Engenheiro de Produção. Neste sentido, houve um movimento por parte da coordenação de curso de várias instituições de ensino superior em Portugal tendo-se decidido alterar a designação do curso para Engenharia e Gestão Industrial, com base em três pressupostos: aumentar a atratividade desta área da Engenharia junto dos alunos do ensino secundário, uniformizar as várias designações existentes no país para a mesma área e para responder à recente criação do grau de especialista reconhecido pela Ordem dos Engenheiros.

Em 2006 foi feito o pedido de adequação do curso ao Processo de Bolonha em que se privilegiou, na formação dos alunos, o aumento da componente prática/ laboratorial e a criação de projetos interdisciplinares. Estes projetos seguem um modelo de aprendizagem que reduz a fragmentação disciplinar, através da articulação entre a teoria e a prática e da interação entre as várias disciplinas que é promovida com o desenvolvimento do projeto que se gera num ambiente cooperativo (Bédard, Lison, Dalle, Côté \& Boutin, 2012; Edström \& Kolmos, 2014; Jollands, Jolly \& Molyneaux, 2012; Kolmos \& Holgaard, 2010). Com base nestes princípios, a aprendizagem baseada em projetos interdisciplinares foi implementada em três momentos do curso $\left(1^{\circ} 7^{\circ}\right.$ e $8^{\circ}$ semestre $)$, em que os alunos trabalham em equipas alargadas, com vista a resolver um problema aberto para o qual convergem os conteúdos das várias disciplinas do mesmo semestre. Decorridos 10 anos da implementação do modelo de aprendizagem baseada em projetos interdisciplinares, destaca-se a sua importância no currículo do MIEGI, pelo facto de a aprendizagem dos alunos se desenvolver num ambiente interdisciplinar e cooperativo, privilegiando-se o desenvolvimento de competências e a aproximação à prática profissional (Fernandes, Flores y Lima, 2012; Fernandes, Mesquita, Flores y Lima, 2014; Lima et al., 2012; Lima, et al., 2014; Lima, Mesquita y Flores, 2014; Van Hattum-Janssen y Mesquita, 2011).

É assim que o MIEGI constitui um estudo de caso para analisar e articular as dimensões pedagógicas e curriculares na formação inicial e, principalmente, os desafios da docência universitária.

\section{Metodologia}

O estudo que se apresenta neste artigo procura analisar de forma integrada três dimensões que configuram um modelo de desenvolvimento curricular no ensino superior: elementos do currículo, competências e perfil profissional, considerando um caso particular-MIEGI (Mesquita, 2015). Neste sentido, o design metodológico segue uma abordagem dominantemente qualitativa e, por isso, estabelece-se uma relação direta entre a problemática em análise e os dados. Trata-se de uma pesquisa que se desenvolveu em três fases durante três anos consecutivos (2010-2013), tal como se ilustra na Figura 1, numa evolução do seu contexto para o aprofundamento da análise do estudo de caso com base nas perspetivas dos alunos, dos professores e dos profissionais, sustentadas pelo referencial teórico desenvolvido ao longo da investigação.

\section{Recolha de dados}

Na primeira fase de investigação, optou-se por realizar uma análise documental diversificada e detalhada, com vista a caracterizar o contexto no qual este estudo se insere que incluiu, entre outros, documentos europeus relacionados com o ensino superior, nomeadamente no que diz respeito ao Processo de Bolonha; documentos de associações profissionais; planos curriculares nacionais e internacionais referentes à Engenharia e Gestão Industrial. A informação recolhida e analisada nesta fase da pesquisa, suportada por uma intensa revisão da literatura sobre a temática em 
Figura 1. Ilustração das fases do design metodológico



Referencial Teórico

Desenvolvimento curricular no ensino superior -inspirado em Zabalaza (2009)

estudo, permitiu construir e validar o instrumento no qual se centra a segunda fase de recolha de dados que consistiu na aplicação de um inquérito por questionário a alunos $(\mathrm{n}=115)$, a professores $(\mathrm{n}=25)$ do Mestrado Integrado em Engenharia e Gestão Industrial e a profissionais da área $(\mathrm{n}=112)$. A principal finalidade era conhecer as perceções dos participantes sobre várias dimensões ligadas à formação inicial em Engenharia e Gestão Industrial.

Na terceira e última fase, procurou-se uma análise mais refinada e aprofundada, relativamente a um conjunto de dimensões que emergiram dos dados quantitativos. Dessa forma, foram escolhidos diferentes métodos qualitativos, de acordo com as especificidades inerentes a cada grupo de participantes, com vista a alcançar uma compreensão mais alargada da problemática de estudo, nomeadamente narrativas com alunos do último ano do miegi $(n=33)$, entrevistas a profissionais entre os quais antigos alunos do miegi $(n=15)$, quatro grupos focais realizados a professores do miegi $(n=14)$ e oito grupos focais alunos realizados com alunos do $1^{\circ}$ ao $4^{\circ}$ ano $(n=30)$.

\section{Análise de dados}

Neste estudo foi realizada uma análise integrada dos dados recolhidos ao longo de todas as fases, com o objetivo de compreender a complexidade, abrangência e profundidade do caso. A triangulação é um processo fundamental, não só para garantir a integração dos dados, de modo a atingir maior profundidade e riqueza da informação recolhida, mas também para garantir a sua validade (Bryman, 2012; Denzin \& Lincoln, 1994; Miles \& Huberman, 1994). A triangulação prevê a combinação de "dois ou mais pontos de vista, fontes de dados, abordagens teóricas ou métodos de recolha de dados numa mesma pesquisa por forma a que possamos obter como resultado final um retrato mais fidedigno da realidade ou uma compreensão mais completa do fenómeno a analisar" (Coutinho, 2013, p. 239).

Deste modo, a análise integrada realizada no âmbito desta pesquisa envolve não só a relação entre as suas dimensões principais (currículo, competências e perfil profissional) mas também articula a perspetiva dos participantes no processo (alunos, professores 
e profissionais). As conclusões decorrentes desta análise integrada permitem desenvolver uma reflexão mais aprofundada sobre o desenvolvimento do currículo no ensino superior, particularmente sobre inovação curricular e as implicações que daí derivam para o trabalho e desenvolvimento profissional dos docentes universitários.

\section{Resultados}

Os resultados decorrentes deste estudo encerram pressupostos curriculares e pedagógicos que permitem identificar três desafios que atualmente se colocam na docência universitária. O primeiro considera a relação entre a planificação do professor e a sua ação pedagógica, incluindo o processo de seleção dos conteúdos e as estratégias de ensino. O segundo reforça a importância da criação de espaços interdisciplinares com vista ao desenvolvimento de competências dos alunos. O terceiro coloca a ênfase na avaliação, enquanto um dos principais elementos potenciadores da inovação curricular. Estes desafios constituem um ponto de partida relevante para uma reflexão mais aprofundada sobre a docência universitária, nomeadamente ao nível das suas implicações para o trabalho e desenvolvimento profissional dos professores.

\section{Da planificação à ação pedagógica}

A planificação é uma atividade complexa na medida em que interage com todos os outros aspetos do ensino e é influenciada por muitos fatores. De acordo com Arends (2008), abrange quase tudo o que os professores fazem, tornando-se parte de um ciclo educacional mais geral. A planificação assume, por isso, uma importância fulcral do ponto de vista pedagógico e operacional, dado que tem implicações na forma como o aluno aprende; um dos elementos chave inerentes à planificação é a definição dos objetivos de aprendizagem. O papel dos objetivos remete para uma interpretação do que é esperado na prática, funcionando como "mapas de estrada" (Arends,
2008, p. 108) que auxiliam os professores e os alunos a situarem-se no processo de ensino e aprendizagem, "para onde vão e quando chegam ao destino" (idem; ibidem). Também na perspetiva de Biggs (2012), os objetivos são o ponto central do currículo que permite definir os restantes pressupostos relacionados com o processo de ensino e aprendizagem.

No âmbito do nosso estudo foram analisados os resultados de aprendizagem de 60 disciplinas do MIEGI, com vista a identificar uma relação entre os resultados de aprendizagem definidos pelos professores e as competências técnicas e transversais associadas ao perfil profissional. Uma das conclusões deste estudo revela que os resultados de aprendizagem definidos pelos professores concentram-se sobretudo ao nível das competências técnicas (Mesquita, Lima, Flores, Marinho-Araújo \& Rabelo, 2015). No entanto, para as atividades que se realizam no âmbito das disciplinas, são contemplados elementos que também potenciam o desenvolvimento das competências transversais, especificamente atividades em que os alunos participam ativamente (e.g. apresentações orais em inglês sobre um assunto da disciplina), o que não transparece na planificação do professor. Tal pode ser justificado pelas dificuldades na definição dos objetivos (Heywood, 2005; Hughes, 2012), sobre tudo pela tendência em elaborar longas listas de objetivos que acabam, assim, por perder, em muitos casos, utilidade e relevância. Stice (1979) sugere que existem outros constrangimentos no processo de definição dos objetivos, por exemplo: para o professor o processo de definição dos resultados de aprendizagem é encarado como uma operação burocrática e, por isso, não dedica muito tempo e reflexão nessa operação.

A passagem da planificação para a ação é, efetivamente, um dos grandes desafios da prática docente e, neste sentido, recomenda-se que a planificação seja suficientemente flexível para que haja espaço para os imprevistos decorrentes da interação pedagógica, do perfil dos alunos, entre outras variáveis que podem 
acontecer na sala de aula. Segundo Arends (2008), a planificação só é útil para a prática docente se puder ser alterada ao longo do tempo. Por exemplo: se uma determinada atividade pedagógica não estiver a funcionar, o professor deve ser capaz de a reajustar ou alterar para que tenha impacto na aprendizagem dos alunos. Para isso é importante ir analisando o feedback dos alunos que, muitas vezes, pode ser a linguagem não-verbal, o nível de envolvimento ou entusiasmo que vão demonstrando. O funcionamento de cada disciplina varia consoante a interação do professor e os alunos, isto é, a forma como os alunos reagem à planificação do professor. É neste momento que se evidencia a motivação e envolvimento dos alunos na aprendizagem. Os exemplos apresentados realçam a importância que a relação entre a teoria e a prática assume na motivação e envolvimento dos alunos nos conteúdos desenvolvidos e nas atividades concretizadas.

\footnotetext{
"Em Cálculo sempre que dávamos alguma coisa nova nós fazíamos logo exercícios, sempre de forma equilibrada, de forma a irmos acompanhando. Em Álgebra era ao contrário: primeiro teoria, teoria, teoria e depois prática, prática, prática. (Grupo Focal Alunos 1.1. Pl).

"[...] às vezes estamos numa parte da matéria e eu ainda não consigo fazer exercícios que estão para trás; e depois fico desmotivada nas aulas porque não consigo acompanhar. Às vezes não é fácil acompanhar o ritmo que os professores vão impondo." (Grupo Focal Alunos 1.2. P4).
}

Nesta perspectiva, o apoio ao aluno é fundamental e também deve ser planeado pelo professor no sentido de definir momentos para recolher feedback sobre o que está a acontecer no processo de ensino e aprendizagem. Este apoio deriva das necessidades dos alunos e, portanto, é sempre uma dimensão imprevisível: Quando será preciso? Que tipo de apoio? Em que circunstâncias? Daí que a planificação do professor deva ser, tanto quanto possível, flexível e dinâmica, no sentido de atender a estas situações e permitir os reajustamentos e as alterações necessárias. Os próximos exemplos ilustram a importância do apoio aos alunos ser realizado pelo professor durante o processo de ensino e aprendizagem, na logica de garantir que eles sejam capazes de auto regularem a sua aprendizagem.

\begin{abstract}
"Não basta dizer que vamos trabalhar em casa porque eu até trabalho, mas eu preciso de apoio, preciso de alguma orientação, preciso que os objetivos estejam claros e não estão [...] também é preciso de haver o mínimo de planeamento do professor." (Grupo Focal Alunos 4.2. P2).
\end{abstract}

A seleção dos conteúdos a abordar é uma das maiores preocupações dos professores na planificação de uma determinada disciplina, pela relevância que assumem na ação pedagógica. Trata-se de uma tarefa exigente para o professor, na medida em que implica um processo de tomada de decisão que deve ser criterioso e adequado:

\footnotetext{
"As disciplinas que dou, na sua maioria, são herdadas. No $1^{\circ}$ ano, por exemplo, já havia muitos conteúdos e até material definido para ser utilizado, mas eu incluí algumas coisas ou fui adaptando [...] às vezes, a dificuldade do professor está aí, em selecionar a matéria, sobretudo numa disciplina de 'Introdução' em que podemos falar de tudo e que qualquer coisa ligada à EGI [Engenharia e Gestão Industrial] faria sentido.” (Grupo Focal Professores 3. P3).
}

Efetivamente, a seleção dos conteúdos curriculares depende da natureza da disciplina e dos objetivos de cada disciplina. A complexidade dos conteúdos é, um critério a considerar acerca do modo de os abordar na sala de aula com os alunos. Não podem ser eliminados porque são complexos, pelo que o 
professor tem de encontrar e definir estratégias de forma a apoiar a compreensão desses mesmos conteúdos; o professor pode adotar várias estratégias em contextos de ensino e aprendizagem, tais como: concept cartoons (Keogh \& Naylor, 1999); mapas conceptuais (Turns, Atman \& Adams, 2000); exemplos baseados na realidade (Cowan, 2006). Este último caso tornase visível nos dados recolhidos, especificamente por parte de um professor que não tem flexibilidade na seleção de conteúdos, mas que procura trabalhar esses conteúdos para que os alunos os sintam como relevantes para a sua aprendizagem.

"[...] de uma forma geral, há matéria que tem de ser dada, que faz parte do currículo e aí nunca temos muita margem para mudar o que quer que seja, porque aqueles conceitos têm de ser dados. Agora os exemplos, eu tento contextualizar com a área em que estou a dar a disciplina. Se é eletrónica eu tento dar um exemplo que tenha algum controlo de processos; se é têxtil eu falo em fios de costura, em fibras; [...] o processo em si é o mesmo, o que eu faço é dar-lhe outra cara, para que seja mais familiar para o aluno. Eu comecei a fazer isto porque os alunos pareciam ter aversão ao X ou ao Y. Por muito que eu dissesse que o $\mathrm{X}$ poderia ser qualquer coisa, eles não conseguiam perceber que coisa poderia ser essa, não conseguiam articular essa parte. A partir do momento em que chamo ao $\mathrm{X}$ fios elétricos a compreensão deles é diferente, torna-se menos abstrato para eles." (Grupo Focal Professores 3. P1).

Tornase, portanto, pertinente recuperar a ideia da motivação e envolvimento dos alunos. A ligação entre a teoria e a prática é uma questão crucial para eles, o que se cruza com a relevância dos conteúdos que emerge dos dados recolhidos como um fator decisivo para a sua motivação, justificada pela relação com o que estão a aprender e a sua utilidade para a prática profissional.
"[...] darmos uma matéria e vermos logo onde é que aquilo se aplica, ver onde é que aquilo faz sentido e onde é que nos vai ajudar, isso é importante. Nós damos as coisas e nunca sabemos bem onde é que vamos aplicar, se vamos precisar ou não. E se soubermos eu acho que a nossa motivação aumenta." (Grupo Focal Alunos 1.1. P1).

Então, a escolha das metodologias de ensino e aprendizagem mais adequadas e relevantes é fundamental para a motivação e envolvimento dos alunos na aprendizagem, para a articulação dos conteúdos, considerando também a articulação entre a teoria e a prática. Na perspetiva dos professores, a relevância e articulação dos conteúdos é essencial no processo de ensino e aprendizagem e os excertos que se seguem ilustram a preocupação com a utilização de uma abordagem que permita uma melhor compreensão dos conteúdos.

\footnotetext{
"O que faço é mostrar-lhes a necessidade da teoria, colocando-os a resolver um exercício analiticamente e depois eles não conseguem, não conseguem fazer. Então aí eu carrego com a teoria. No fundo, faço-os sentir a necessidade, sentir os problemas, para eles verem no que é que a teoria se torna importante. No momento em que comecei a fazer isto os alunos começaram a mexer-se melhor dentro dos conteúdos.” (Grupo Focal Professores 3. P1).
}

Efetivamente, o professor tem um papel primordial na gestão e abordagem dos conteúdos, uma vez que influencia a forma como os alunos os compreendem e, consequentemente, com repercussões ao nível da motivação e envolvimento dos alunos nas atividades e no contexto geral da disciplina.

As estratégias de transposição didática levadas a cabo pelo professor assumem uma importância fulcral no processo de aprendizagem. Os aspetos a considerar na apresentação dos conteúdos implicam, segundo Arends (2008), clareza na mensagem 
a transmitir, que pode ser assegurada através da planificação, organização e experiência do professor; elos explicativos e exemplos, que permitem reforçar a mensagem, agilizando o processo de compreensão por parte do aluno; sinalizadores e transcrições que proporcionam a articulação entre diferentes tópicos e reforçam o que é mais importante; e ainda entusiasmo que, usado de forma equilibrada e não exagerada, pode ajudar a captar a atenção dos alunos. Importa, por isso, que no planeamento do processo de ensino e aprendizagem o professor contemple não só os conteúdos que foram selecionados mas a abordagem que irá utilizar para a transposição didática.

\section{Da fragmentação curricular à interdisciplinaridade}

A metodologia e as atividades promovidas nas situações pedagógicas têm implicações no papel que o professor e o aluno assumem e, consequentemente, na forma como estes entendem o processo de ensino e aprendizagem, que poderá incidir numa abordagem mais centrada no professor ou mais centrada no aluno (Prosser \& Trigwell, 2000; Ramsden, 2004).

Criar ambientes de aprendizagem que retirem os alunos da passividade a que estão habituados é um dos grandes desafios atuais na prática docente (Darling-Hammond, 1997; Eekelen, Boshuizen \& Vermunt, 2005; Fitzmaurice, 2010; Vermunt \& Verloop, 1999). A visão dos professores confirma este pressuposto. Perante as atividades propostas, os professores denotam falta de envolvimento por parte dos alunos e aí reside uma das suas maiores dificuldades:

\footnotetext{
"Eu gostava que eles fossem mais ativos e não fossem tão passivos, que não esperassem por mim para fazer as coisas na sala de aula. E isto não é só ao nível dos exercícios, é também ao nível de colocarem perguntas até quando estamos na parte de exposição da matéria, há sempre lugar a colocar questões, eu provoco-os a isso e aí eles também podiam ser mais ativos." (Grupo Focal Professores 4. P2).
}

Associado com este pressuposto estão as perspetivas dos profissionais que sugerem um conjunto diversificado de atividades no sentido de estimular o envolvimento dos alunos no processo de ensino e aprendizagem. Das atividades sugeridas poderemos mencionar simulações e jogos, palestras de profissionais, estágios em empresas, estudos de caso, projetos e visitas a empresas.

\begin{abstract}
"Uma coisa é lembrar outra coisa é compreender. E os jogos são uma prática simulada, portanto, as pessoas têm de mexer com coisas, têm de jogar, têm emoções há mistura. [...] não há nada como mexer nas coisas, como organizar, verificar, medir, fisicamente mesmo. $\mathrm{O}$ aluno fica com essa vivência, com essa experiência, que é muito mais fácil transpor para a realidade. Quando ele tiver uma determinada tarefa para realizar na prática profissional, o que ele se vai lembrar foi a situação que viveu com o jogo [...] Eu acho que a Engenharia e Gestão Industrial tem de evoluir para as práticas simuladas, porque é a melhor maneira de ensinar e é a melhor maneira de aprender." (Profissional 4).
\end{abstract}

Esta é uma perspetiva partilhada e, por isso, consensual entre os participantes, sendo também consistente com a literatura, que recomenda a inclusão de atividades no desenvolvimento do currículo dos cursos de Engenharia centradas no desenvolvimento de competências (Dym, Agogino, Eris, Frey \& Leifer, 2005; Jollands et al., 2012; Lima, et al., 2014; van Hattum-Janssen \& Mesquita, 2011) e que envolvem os alunos no próprio processo de aprendizagem no sentido das chamadas pedagogies of engagement (Smith, Sheppard, Johnson \& Johnson, 2000).

No MIEGI os projetos interdisciplinares de aprendizagem são entendidos pelos alunos e pelos professores como uma mais-valia na formação inicial (Fernandes et al., 2014), na medida em que se trata de um modelo de aprendizagem que tem proporcionado experiências de aprendizagem de tal forma 
significativas que emergem nos dados recolhidos no âmbito deste estudo:

"Eu acho que fazer os projetos em empresas foi a melhor coisa que me aconteceu durante a universidade, é mesmo uma mais-valia porque tu vês mesmo como as coisas são e percebes que são diferentes das coisas como te são dadas numa aula. Por exemplo, a dificuldade de teres dados. Num exercício tu tens os dados todos completos e com sentido para poderes chegar ao resultado final, mas numa empresa, onde vais passar grande parte da tua vida, não; tens dados dispersos e incompletos e, para fazeres uma determinada mudança ou melhoria ou o que seja, tens de ter os outros dados e aí é que está o nosso trabalho." (Grupo Focal Alunos 4.2. P1).

"Com os projetos, por exemplo, nós não dizemos vamos estudar, nós dizemos vamos trabalhar e eu acho que isto já diz muito do que acontece. Realmente trabalhamos, porque implica ligar aquilo que damos nas aulas com a prática, não estamos a estudar os conceitos e a decorar e a fazer exercícios atrás de exercícios, não, estamos a trabalhar." (Grupo Focal Alunos 4.1. P2).

"[...] acho que é a melhor maneira de aplicar a teoria na prática; e não é a teoria que demos antes é a teoria que estamos a dar naquele momento, o que torna muito mais forte aquilo que estamos a aprender." (Grupo Focal Alunos 3.1. P4).

Também para os professores os projetos interdisciplinares constituem experiências de ensino significativas, dado que alteram a relação pedagógica no sentido de uma interação mais dinâmica.

"Este ano foi a primeira vez que participei no projeto do $1^{\circ}$ ano e fiquei surpreendido ao ver que eles conseguiam aplicar no projeto uma grande parte dos conceitos de Química porque estava relacionado com a reciclagem daqueles produtos eletroeletrónicos; e com este exemplo penso que eles conseguem ver bem, logo ali no $1^{\circ}$ ano, a importância que a Química tem, a ligação com o que eles fazem na produção, quando poderia ser menos evidente essa aplicação se não tivessem o projeto." (Grupo Focal Professores 4. P3).

"Porque o que eu gostei mais do projeto foi precisamente terem sido os alunos a puxarem por mim, a porem-me a pensar, a ir pesquisar e a partilhar. Houve alturas em que era mesmo uma partilha de mim para os alunos e dos alunos para mim. Eu nunca pensei que quando fosse dar aulas fosse ter uma experiência assim!"' (Grupo Focal Professores 3. P2).

O papel do professor nestes contextos é fundamental porque, ao privilegiar momentos de aprendizagem ativa, potencia oportunidades para os alunos desenvolverem competências, não só transversais que se distinguem no âmbito das metodologias ativas, mas também técnicas que assumem outra dimensão quando os alunos estão inseridos num ambiente em que a teoria e a prática se encontram articuladas. Contudo, a interdisciplinaridade confere ao projeto uma complexidade que coloca dificuldades ao nível da prática docente, nomeadamente no que diz respeito ao seu planeamento e gestão durante o processo (Fernandes, Lima \& Flores, 2009) que exige coordenação e monitorização. Todavia, esta abordagem coloca também os professores num ambiente cooperativo que se torna essencial para a qualidade do ensino (Zabalza, 2009).

\section{Da avaliação à inovação}

A avaliação é um processo onde se pode tornar visível a coerência entre todos os elementos de desenvolvimento do currículo: relação entre os objetivos e as atividades desenvolvidas, importância atribuída aos conteúdos, metodologia apropriada no contexto da formação inicial e os recursos que são disponibilizados (Zabalza, 2009). Muitas vezes a avaliação torna-se incoerente com a abordagem utilizada na sala de aula, o que traz algumas dificuldades para a 
prática docente. Ou seja, se o professor utiliza uma abordagem de modo a ir ao encontro das necessidades dos alunos, para que compreendam os conteúdos e se sintam motivados, o modelo de avaliação pode depois estabelecer uma rutura com esta lógica, se for centrado numa conceção que leve o aluno a memorizar, a reproduzir e não a compreender.

"O exemplo ajuda para eles compreenderem a matéria mas depois eles no teste não vão pensar sobre a ferramenta $\mathrm{X}$, eles vão reproduzir a matéria abstrata. Quer dizer, usamos exemplos e isto e aquilo e depois a forma de avaliar é quase contra natura ao objetivo ou à intenção com que usamos os exemplos." (Grupo Focal Professores 3. P1).

De acordo com Dochy e McDowell (1997), a avaliação deve ser encarada como uma ferramenta para a aprendizagem, permitindo processos que conduzem a uma melhoria da formação do aluno, tais como: autorregulação, desenvolvimento de competências e reflexão sobre a prática. Existem estudos que revelam que a forma como os alunos encaram a avaliação determina a forma como gerem a sua aprendizagem (Gibbs, 1999; Pereira \& Flores, 2012; Watering, Gijbels, Dochy \& Rijt, 2008). Também os dados decorrentes deste estudo realçam este aspeto:

\section{"[...] muitos professores depois dizem que tiramos boas notas, que temos a vida facilitada, mas tam- bém se nós sabemos que é aquilo que vai sair [nos testes], que é aquilo que é esperado, para que é que vamos estudar outras coisas? Nós preparamo-nos para aquilo que esperam de nós, não é? Não vamos inventar. E aquilo que esperam de nós é decorar exatamente aquilo que está nas sebentas, portanto, nem depende do que nós pensamos sobre o assun- to." (Grupo Focal Alunos 3.2. P2).}

Reconhece-se, assim, que a avaliação sumativa assume destaque nas práticas avaliativas no ensino superior e o curso no qual este estudo assente não é exceção. Os testes escritos são instrumentos de avaliação que estão presentes em todas as disciplinas, constituindo o maior peso para a avaliação final. Denota-se a tentativa e a preocupação em implementar práticas de avaliação para além dos convencionais testes (artigos, discussões, apresentações, entre outros) numa dimensão mais formativa, destacando-se ainda a necessidade de dar mais ênfase ao processo.

\footnotetext{
"Se os testes são necessários para tentar sermos mais objetivos, acho que não são bons para aqueles alunos que no papel não conseguem mostrar o quanto são bons; e este processo de avaliação acaba por desvalorizar este tipo de perfil de aluno. [...] A parte do teste eu gostava que valesse menos mas eu tenho de seguir as diretrizes daquilo que já está a ser feito; eu acho que devia dar-se mais valor ao processo que o aluno desenvolve durante o semestre, como é que ele evolui, como é que ele trabalha e olha para ofeedback que damos... e não centrarmo-nos num teste final que pode não refletir realmente aquilo que o aluno aprendeu. Eu acho que ter vários elementos de avaliação ajuda a normalizar, digamos assim, porque todo o processo é considerado." (Grupo Focal Professores 3. P2).
}

Contudo, quando os alunos comparam os testes escritos com outras atividades que realizam (e.g. trabalhos práticos), enfatizam a importância de inovar a forma de avaliação, no sentido de atividades mais significativas para a aprendizagem, em que têm a oportunidade de construir conhecimento de forma ativa e participativa, desenvolvendo, assim, competências essenciais para a prática profissional.

\footnotetext{
"No trabalho eu consegui relacionar a matéria toda, estar envolvida, explicar aos outros algumas partes até mais complexas e tudo e depois no teste espalheime completamente. Eu não sei o que é que aconteceu. Eu sei que sabia a matéria mas correu-me
} 
mesmo mal e tive de ir a exame. Não parece coerente porque os testes deveriam ser a forma mais objetiva de avaliar, pelo menos é o que os professores dizem, mas acho que afinal não é, porque neste caso não reflete o que eu realmente sabia. Até porque no trabalho nós vamos mais fundo, estamos mais atentos aos pormenores, conseguimos relacionar as ideias e os conceitos e num teste a lógica acaba por ser diferente, porque se limita ao exercício com uma única solução e pronto.” (Grupo Focal Alunos 3.1. P1).

Assim, diversificar os métodos de avaliação implica diversificar as atividades inerentes ao processo de ensino e aprendizagem, com vista a construir espaços em que os alunos possam efetivamente refletir sobre o que aprendem, como aprendem e com quem aprendem. A inovação na forma de avaliar pressupõe o desenvolvimento de competências e, nesse sentido, utilizar diferentes métodos de avaliação permite avaliar várias competências (Struyven, Dochy \& Janssens, 2005), comparativamente com um teste no final do período de aprendizagem. A inovação passa igualmente por articular a avaliação sumativa com a avaliação formativa, isto é, o professor pode incluir práticas formativas, utilizando o feedback, que no sentido da ajuda à aprendizagem dos alunos. O feedback sobre os testes escritos não é uma prática comum no ensino superior, tal como podemos confirmar pelos resultados obtidos. Os alunos destacam que, de uma forma geral, a informação que obtêm centra-se exclusivamente na nota final do teste escrito (enfoque no resultado).

"Por acaso a professora $\mathrm{X}$ trouxe os testes para nós vermos o que tínhamos feito. E nós sabendo que isso vai ser feito temos mais vontade de ir à aula, porque temos a oportunidade de melhorar e de aprender porque a professora explica. Enquanto que nas outras disciplinas isto não acontece, nem se quer a resolução é dada e assim nem sabemos o que erramos o que acertamos. E se na altura não soubemos fazer aquilo, vamos ficar sem saber fazê-lo porque acabamos por não ter feedback." (Grupo Focal Alunos 3.1. P4).

A investigação tem demonstrado os benefícios da avaliação formativa para a aprendizagem são inquestionáveis (Black \& Wiliam, 1998), com particular destaque para caráter formativo do feedback (Boud \& Molloy, 2013; Nicol, Thomson \& Breslin, 2014; Orsmond, Maw, Park, Gomez \& Crook, 2013; Price, Handley, Millar \& O'Donovan, 2010). No contexto deste estudo, o feedback destaca-se como um elemento que naturalmente se relaciona com o desenvolvimento de um currículo de qualidade e, neste sentido, os alunos enfatizaram a sua importância na aprendizagem, pelas experiências de feedback no contexto dos projetos interdisciplinares.

"Por exemplo, no projeto o feedback era constante e isso foi mesmo muito bom para melhorarmos e isso fez de nós melhores alunos e fez com que evoluíssemos muito ao longo do tempo. O relatório, por exemplo, não tinha só coisas ai isto está tão bem-engraçado, porque também tinha um ou dois comentários positivos, mas a maioria eram aspetos para melhorar. Então, nós pegamos nisso e melhorámos. Se nós não tivéssemos este foco, esta visão que nos guiasse -é por aqui que têm de melhorar - nós não sabíamos, porque quando fazemos achamos que está bem porque estamos a dar o nosso melhor à partida." (Grupo Focal Alunos 1.1. P1).

"O feedback também é importante noutro sentido que é alinharmos os pontos de vista e isto aconteceu com o meu grupo. Com base no feedback dado por uma professora nós percebemos de imediato que ela não tinha percebido a nossa ideia, e aí também percebemos que não tínhamos transmitido a ideia da melhor forma, então explicamos à professora e ela entendeu melhor e ali conseguimos alinhar melhor os nossos pontos de vista. Nós percebemos o dela e 
ela percebeu o nosso. Mas assim também tivemos a oportunidade de contra argumentar.” (Grupo Focal Alunos 1.1. P3).

O feedback surge também como uma ferramenta de interação entre o aluno e professor e entre os alunos no sentido de melhorar determinados aspetos relacionados com a aprendizagem. A questão que se coloca pode ser: como promover ofeedback? A resposta torna-se complexa porque envolve vários pressupostos, sendo um deles a natureza e o propósito do feedback, pois o efeito que se pretende para a aprendizagem vai determinar o procedimento que deve ser adotado pelo professor para fornecer esse feedback (Price et al., 2010). Importa que seja um feedback que não provoque alienação nos alunos, "por acontecer demasiado tarde, vago, confuso e inconsistente" (Orsmond et al., 2013, p. 241). É neste contexto que vários estudos identificam fragilidades na implementação de processos avaliativos mais complexos, sendo um deles o aumento do volume de trabalho (Fernandes et al., 2009; Flores, Veiga-Simão, Barros \& Pereira, 2014; Gijbels \& Dochy, 2006). Por isso, os professores têm de ser preparados para estas práticas, que são complexas mas contribuem diretamente para a qualidade do ensino e da aprendizagem no ensino superior.

\section{Considerações finais}

A relevância das dimensões curriculares e pedagógicas no contexto do ensino superior tem estado cada vez mais presente na literatura com destaque para o papel do professor na medida em que é um agente decisivo nos processos de inovação e mudança das universidades, sobre tudo no que diz respeito à qualidade do processo de ensino e aprendizagem. No entanto, não são muitos os estudos que discutem, de forma aprofundada, as questões e as orientações necessárias para a docência universitária.

Neste artigo apresentamos desafios que se colocam à prática docente no ensino superior que permitem refletir criticamente sobre o desenvolvimento do currículo, nomeadamente sobre a importância da relação entre a planificação e a ação, sobre as implicações da fragmentação curricular e a relevância das práticas interdisciplinares (de que é exemplo os projetos interdisciplinares presentes no currículo do MIEGI) e ainda sobre a predominância de modelos mais tradicionais de avaliação que é preciso inovar e diversificar. Conclui-se que o domínio do conhecimento técnico-científico não é a única competência do professor do ensino superior; outras são igualmente importantes à prática docente nomeadamente as competências de planificação (Devlin \& Samarawickrema, 2010; Tigelaar, Dolmans, Wolfhagen \& Van der Vleuten, 2004; Zabalza \& Cerdeiriña, 2010), de comunicação (Cowan, 2006) e de trabalhar em equipa (Zabalza, 2009). Os docentes universitários, muitas vezes, e por várias razões, não estão disponíveis para investir na sua prática pedagógica. Seguindo este pressuposto, o relatório da Comissão Europeia para a melhoria da qualidade do ensino e da aprendizagem das instituições do ensino superior considera que os professores do ensino superior devem ser formados como professores e nesse sentido recomenda que "todos os docentes das instituições de ensino superior devem em 2020 possuir formação e qualificação pedagógica. A sua formação contínua deve constituir um requisito para os professores do ensino superior" (European Commision, 2013, p. 31). A formação pedagógica assume, por isso, uma importância fulcral no desenvolvimento profissional dos professores do ensino superior (Pinto, 2008) desde que seja contextualizada, ou seja, considerando "a resolução de problemas pedagógicos emergentes em cada situação" (Esteves, 2008, p. 108). Esta é uma perspetiva também partilhada por outros autores (Reimann \& Wilson, 2012) que valorizam as práticas de formação para a melhoria dos processos de ensino e aprendizagem, tal como os dados empíricos recolhidos no âmbito deste estudo sugerem. 


\section{Referencias}

Alonso, L. (2000), "Desenvolvimento curricular, profissional e organizacional: uma perspetiva integradora de mudança", en Revista Território Educativo, 7, pp. 33-42.

Arends, R. (2008), Aprender a Ensinar (7th ed.), Madrid, McGraw-Hill.

Barnett, R. (1994), The limits of competence: knowledge, higher education and society, Buckingham, SRHE/Open University Press.

Barnett, R. y K. Coate (2005), Engaging the Curriculum in Higher Education, Maidenhead, Open University Press/ Society for Research Into Higher Education.

Barnett, R., Parry, G., \& Coate, K. (2001) “Conceptualising Curriculum Change", en Teaching in Higher Education, 6(4), pp. 435-449.

Bédard, D., C. Lison, D. Dalle, D. Côté y N. Boutin (2012), "Problem-based and project-based learning inengineering and medicine: determinants of students' engagement and persistance", en Interdisciplinary fournal of Problem-based Learning, 6(2), pp. 7-30.

Biggs, J. (1996), "Enhancing teaching through constructive alignment", en Higher Education, 32(3), pp. 347-364.

Biggs, J. (2012), "What the student does: teaching for enhanced learning", en Higher Education Research E० Development, 31(1), pp. 39-55.

Black, P. y D. Wiliam (1998), "Assessment and classroom learning", en Assessment in Education: Principles, Policy \& Practice, 5(1), pp. 7-74.

Boud, D. y E. Molloy (2013), "Rethinking models of feedback for learning: the challenge of design", en Assessment $\mathcal{E}$ Evaluation in Higher Education, 38(6), pp. 698-712.

Bryman, A. (2012), Social research methods (4th ed.), Oxford, Oxford University Press.

Coutinho, G. (2013), Metodologia de investigação em ciências sociais e humanas: teoria e prática ( $2^{\mathrm{a}}$ ed.), Coimbra, Almedina.

Cowan, J. (2006), On becoming an innovative university teacher: reflection in action, (2nd ed.), Maidenhead, The Society for Research into Higher Education.
Darling-Hammond, L. (1997), Doing what matters most: investing in quality teaching, Nueva York, The National Commission on Teaching and America's Future.

Denzin, N. y Y. Lincoln (1994), Handbook of qualitative research, Thousand Oaks, Sage Publications.

Devlin, M. y G. Samarawickrema (2010), "The criteria of effective teaching in a changing higher education context", en Higher Education Research \& Development, 29(2), pp. 111-124.

Dochy, F. y L. McDowell (1997), "Assessment as a tool for learning", en Studies in Educational Evaluation, 23(4), pp. 279-298.

Dym, C., A. Agogino, O. Eris, D. Frey y L. Leifer (2005), "Engineering design thinking, teaching, and learning", en Fournal of Engineering Education, 94(1), pp. 103-120.

Edström, K. y A. Kolmos (2014), "PBL and CDIO: complementary models for engineering education development", en European fournal of Engineering Education, 39(5), pp. 539-555.

Eekelen, I., H. Boshuizen y J. Vermunt (2005), "Selfregulation in higher education teacher learning" en Higher Education, 50(3), pp. 447-471.

Esteves, M. (2008), "Para a excelência pedagógica do ensino superior", en Sísifo/revista de ciências da educação (7), pp. 101-110.

European Commission (2013), Improving the quality of teaching and learning in Europe's higher education institutions, from <http://ec.europa.eu/education/library/ reports/modernisation_en.pdf $>$ [Fecha de consulta: noviembre 2015].

Fensham, P. (1977), "Dimensions for defining the curriculum", en Studies in Higher Education, 2(1), pp. 89-96.

Fernandes, S., M. A. Flores y R. M. Lima (2012), "Students' views of assessment in project-led engineering education: findings from a case study in Portugal", en Assessment Eै Evaluation in Higher Education, 37(2), pp. 163-178.

Fernandes, S., R. M. Lima y M. A. Flores (2009), "ProjectLed Education from faculty staff's perspective: a 
case study of Engineering Education in Portugal", Paper presented at the 2nd International Research Symposium on PBL (IRSPBL'2009), Melbourne, Australia, pp. 3-4 December.

Fernandes, S., D. Mesquita, M. A. Flores y R. M. Lima (2014), "Engaging students in learning: findings from a study of project-led education", en European fournal of Engineering Education, 39, pp. 55-67.

Fitzmaurice, M. (2010), "Considering teaching in higher education as a practice", en Teaching in Higher Education, 15(1), pp. 45-55.

Flores, M. A., A. Veiga-Simão, A. Barros y D. Pereira (2014), "Perceptions of effectiveness, fairness and feedback of assessment methods: a study in higher education", en Studies in Higher Education, DOI: 10.1080/03075079.2014.881348 [Fecha de consulta: septiembre 2015].

Fraser, S. y A. Bosanquet (2006), "The curriculum? That's just a unit outline, isn't it?", en Studies in Higher Education, 31(3), pp. 269-284.

Gibbs, G. (1999), "Using assessment strategically to change the way students learn", en S. Brown y A. Glasner (eds.), Assessment matters in Higher Education: choosing and using diverse approaches, Buckingham, S.R.H.E. and Open University Press.

Gijbels, D. y F. Dochy (2006), “Students' assessment preferences and approaches to learning: can formative assessment make a difference?", en Educational Studies, 32(4), pp. 399-409.

Heywood, J. (2005), Engineering education: research and development in curriculum and instruction, Piscataway, N.J., IEEE Press.

Hughes, C. (2012), "A case study of assessment of graduate learning outcomes at the programme, course and task level", en Assessment \&ै Evaluation in Higher Education, 38(4), pp. 492-506.

Jollands, M., L. Jolly y T. Molyneaux (2012), "Projectbased learning as a contributing factor to graduates' work readiness", en European Journal of Engineering
Education, 37(2), pp. 143-154.

Keogh, B. y S. Naylor (1999), "Concept cartoons, teaching and learning in science: an evaluation", en International Journal of Science Education, 21(4), pp. 431-446.

Kolmos, A. y J. E. Holgaard (2010), "Responses to problem based and project organised learning from industry", en International Journal of Engineering Education, 26(3), pp. 573-583.

Lima, R. M., D. Carvalho, R. M. Sousa, A. Alves, F. Moreira, D. Mesquita y S. Fernandes (2012), "A project management framework for planning and executing interdisciplinary learning projects in engineering education", en L. C. de Campos, E. A. T. Dirani, A. L. Manrique y N. von Hattum-Janssen (eds.), Project approaches to learning in engineering education: the practice of teamwork, Rotterdam, The Netherlands, SENSE, pp. 53-76.

Lima, R. M., J. Dinis-Carvalho, A. Alves, R. M. Sousa, F. Moreira, D. Mesquita, S. Fernandes y M. A. Flores (2014), "10 anos de PBL-Contributos para a educação em engenharia [extended abstract]", Paper presented at the CNaPPES 2014, Congresso Nacional de Práticas Pedagógicas no Ensino Superior, Porto, Portugal, 5/9.

Lima, R. M., D. Mesquita y M. A. Flores (2014), "Project approaches in interaction with industry for the development of professional competences", Paper presented at the Industrial and Systems Engineering Research Conference (ISERG 2014), Montréal, Canadá, 31 mayo- 3 junio.

Magalhães, A. (2011), "Cenários, dilemas e caminhos da educação superior europeia", en Perspectiva, 29(2), pp. 623-647.

Mesquita, D. (2015), "O Currículo da formação em engenharia no âmbito do Processo de Bolonha: desenvolvimento de competências e perfil profissional na perspetiva dos docentes, dos estudantes e dos profissionais", Tese de Doutoramento, Braga, Portugal, Universidade do Minho.

Mesquita, D., Lima, R. M., Flores, M. A., Marinho- 
Araújo, C., \& Rabelo, M. (2015) "Industrial Engineering and Management Curriculum Profile: Developing a Framework of Competences", en International fournal of Industrial Engineering and Management, 6(3), pp. 121-131, <http://www.iim.ftn.uns.ac.rs/casopis/volume6/ijiem_ vol6_no3_4.pdf> [Fecha de consulta: noviembre 2015].

Miles, M. B. y A. M. Huberman (1994), Qualitative data analysis: an expanded sourcebook (2nd ed.), Thousand Oaks, Sage Publications.

Nicol, D., A. Thomson y C. Breslin (2014), "Rethinking feedback practices in higher education: a peer review perspective", en Assessment \& Evaluation in Higher Education, 39(1), pp. 102-122.

Orsmond, P., S. J. Maw, J. R. Park, S. Gomez y A. C. Crook (2013), "Moving feedback forward: theory to practice", en Assessment \& Evaluation in Higher Education, 38(2), pp. 240-252.

Pereira, D. y M. A. Flores (2012), "Percepções dos estudantes universitários sobre a avaliação das aprendizagens: um estudo exploratório", en Avaliação, $17(2)$, pp. 529-556.

Pinto, P. R. (2008), "Formação pedagógica no ensino superior. O caso dos docentes médicos", en Sísifo/revista de ciências da educação (7), pp. 111-124.

Price, M., K. Handley, J. Millar y B. O’Donovan (2010), "Feedback: all that effort, but what is the effect?", en Assessment \& Evaluation in Higher Education, 35(3), pp. 277-289.

Prosser, M. y K. Trigwell (2000), Understanding learning and teaching: the experience in higher education, Buchingham, Society for Research into Higher Education.

Ramsden, P. (2004), Learning to teach in higher education (2nd ed.), London, Routledge.

Reimann, N. y A. Wilson (2012), "Academic development in 'assessment for learning': the value of a concept and communities of assessment practice", en International Fournal for Academic Development, 17(1), pp. 71-83, DOI: 10.1080/1360144X.2011.586460 [Fecha de consulta: enero 2018].

Smith, K. A., S. D. Sheppard, D. W. Johnson y R. T. Johnson (2005), "Pedagogies of Engagement:
Classroom-Based Practices", en Fournal of Engineering Education, 94(1), pp. 87-101.

Stice, J. E. (1979), "PSI \& Bloom's Mastery Model: a review \& comparison", en Engineering Education, 70(2), pp. 175-180.

Struyven, K., F. Dochy y S. Janssens (2005), “Students' perceptions about evaluation and assessment in higher education: a review", en Assessment छ Evaluation in Higher Education, 30(4), pp. 325-341.

Tigelaar, D., D. Dolmans, I. Wolfhagen y C. van der Vleuten (2004), "The development and validation of a framework for teaching competencies in higher education", en Higher Education, 48, pp. 253-268.

Toohey, S. (2002), Designing courses for higher education, Buckingham, Society for Research into Higher Education.

Turns, J., C. J. Atman y R. Adams (2000), “Concept maps for engineering education: a cognitively motivated tool supporting varied assessment functions", en IEEE Transactions on Education, 43(2), pp. 164-173.

Van Hattum-Janssen, N. y D. Mesquita (2011), "Teacher perception of professional skills in a project-led engineering semester", en European fournal of Engineering Education, 36(5), pp. 461-472.

Veiga-Simão, A., M. A. Flores, A. Barros, S. Fernandes y D. Mesquita (2015), "Perceptions of university teachers about teaching and the quality of pedagogy in higher education: a study in Portugal/Percepciones de los profesores universitarios sobre la enseñanza y la calidad de la pedagogía de la educación superior: un estudio realizado en Portugal", en Infancia y aprendizaje: journal for the study of Eeducation and development, 38(1), pp. 102-143.

Vermunt, J. D. y N. Verloop (1999), "Congruence and friction between learning and teaching", en Learning and Instruction, 9(3), pp. 257-280.

Vieira, F., A. Gomes, C. Gomes, J. L. Silva, M. A. Moreira, M. Melo y P. B. Albuquerque (2002), Concepções de pedagogia universitária-um estudo na Universidade do Minho, Relatório de Investigação, Braga, Universidade do Minho, CEEP. 
Watering, G., D. Gijbels, F. Dochy y J. von der Rijt (2008), "Students' assessment preferences, perceptions of assessment and their relationships to study results", en Higher Education, 56(6), pp. 645-658.

Zabalza, M. (2002), La enseñanza universitária. El escenaria e sus protagonistas, Madrid, Narcea.
Zabalza, M. (2009), Competencias docentes del profesorado universitario: calidad y desarrollo profesional (2nd ed.), Madrid, Narcea.

Zabalza, M. y M. Cerdeiriña (2010), Planificación de la docencia en la universidad: elaboración de las guías docentes de las materias, Madrid, Narcea

\section{Cómo citar este artículo:}

Mesquita, Diana, Maria-Assunção Flores y Rui M. Lima (2018), “Desenvolvimento do currículo no ensino superior: desafios para a docência universitária", en Revista Iberoamericana de Educación Superior (RIES), México, UNAM-IISUE/Universia, vol. IX, núm. 25, pp. 42-61, http://dx.doi.org/10.22201/iisue.20072872e.2019.25.338 [consulta: fecha de última consulta]. 